\title{
Low latitude ionospheric effects of major geomagnetic storms observed using TOPEX TEC data
}

\author{
Y. O. Migoya-Orué ${ }^{1,2}$, S. M. Radicella ${ }^{2}$, and P. Coïsson ${ }^{2}$ \\ ${ }^{1}$ CIASUR - FRT - Universidad Tecnológica Nacional, Tucumán, Argentina \\ ${ }^{2}$ ARPL, the Abdus Salam International Centre for Theoretical Physics, Trieste, Italy
}

Received: 7 October 2008 - Revised: 25 May 2009 - Accepted: 4 August 2009 - Published: 11 August 2009

\begin{abstract}
Low latitude ionospheric effects of two major geomagnetic storms are analysed using TOPEX TEC data for specific satellite passes. The storms are the one that started on 15 July 2000 and the one that started on 8 November 2004. The variation of vertical TEC as a function of latitude along the satellite passes during day-time mostly in the region of the Pacific Ocean have been analysed comparing the storm period with quiet conditions. It has to be noted that for obvious reasons the TEC behaviour over this region cannot be observed using ground-based instruments but TOPEX data give a reasonable overall view of the region covered by the Equatorial Anomaly, just as the storms were developing.

The performance of vertical TEC obtained from GPS derived TEC of global ionospheric maps (GIMs) are compared with the TOPEX data in order to determine their accuracy when storms of this type take place.

The results show that the Equatorial Anomaly TEC peaks move towards the poles by several degrees and increase their intensity with respect to the quiet conditions behaviour for both storms that occurred at different seasons and solar activity level. This behaviour is not well represented by the maps of the different GIMs used in this study. The rate of change obtained from TOPEX TEC were computed to look for vertical TEC spatial gradients variations.
\end{abstract}

Keywords. Ionosphere (Equatorial ionosphere; Ionospheric disturbances) - Magnetospheric physics (Storms and substorms)

\section{Introduction}

The response of the ionosphere to geomagnetic activity is an old and well studied topic in space physics. Geomagnetic activity generates energy inputs that generally take the form

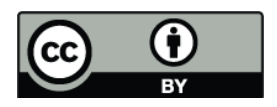

Correspondence to: Y. O. Migoya-Orué (yenca@ictp.it) of enhanced electric fields, currents, and energetic particle precipitation and can significantly modify the ionospherethermosphere system (Prölss, 1995; Buonsanto, 1999).

Two major storm events took place on 15 July 2000 (minimum $D_{s t}=-301 \mathrm{nT}$ recorded on 16 July) and 8 November 2004 (minimum $D_{s t}=-373 \mathrm{nT}$ recorded same day). These storms were the object of several studies, like Basu et al. (2001), Kil et al. (2003).

The former storm started with a coronal mass ejection on 14 July 2000 and then a sudden impulse in the geomagnetic field was recorded late on 15 July to early on 16 July 2000 accompanied with severe storm conditions. Lin and Yeh (2005) analysed ROCSAT-1 data from ion drift meters to examine penetration of electric fields into the low-latitude ionosphere during the July 2000 magnetic storm activity, finding complex signatures near the South Atlantic anomaly region.

In November 2004 there was a moderate increase of proton flux with the maximum around the midnight between 7 to 8 November observed at GOES. The $D_{s t}$ value reached $-373 \mathrm{nT}$ at 07:00 UT on 8 November.

During an ionospheric storm the effects are identified with the corresponded phases, namely: a) the initial or positive phase, which lasts for a few hours and presents electron density and electron content greater than normal; b) the main or negative phase, when these quantities are smaller than normal values and can last even various days. The time of the day is also important: negative effects tend to be stronger at night and early morning but weaker in the afternoon and evening (Hunsucker and Hargreaves, 2003).

In this work we investigate the effects caused by these two intense storms on the development of the Equatorial Anomaly (EA) of the ionosphere as shown in the vertical TEC along single passes of TOPEX/Poseidon satellite. These passes were examined together with other quiet prestorm passes, which follow similar tracks at more or less the same local time.

Other ionospheric storms studies, like those of Lynn et al. (2004) and Yizengaw et al. (2005) have combined

Published by Copernicus Publications on behalf of the European Geosciences Union. 


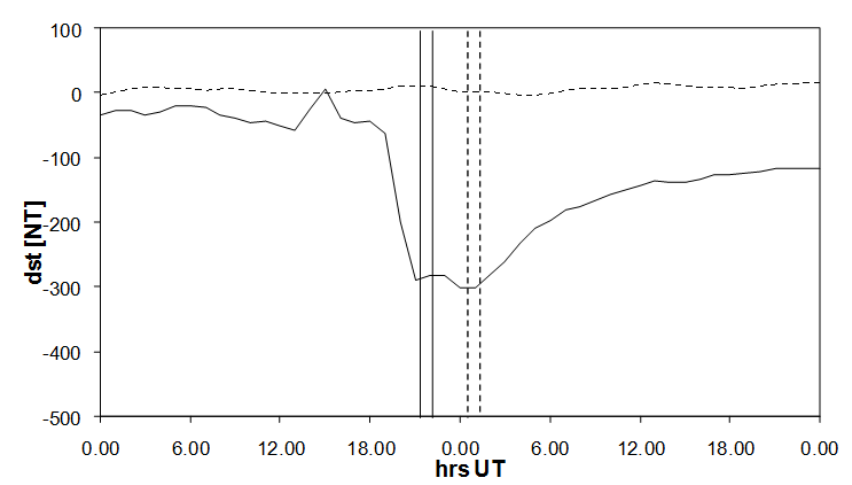

Fig. 1a. $D_{s t}$ indexes of disturbed days 15 and 16 July 2000 in solid line and quiet days 6 and 7 July 2000 in dashed line. The vertical lines indicate beginning and end of TOPEX/Poseidon passes.

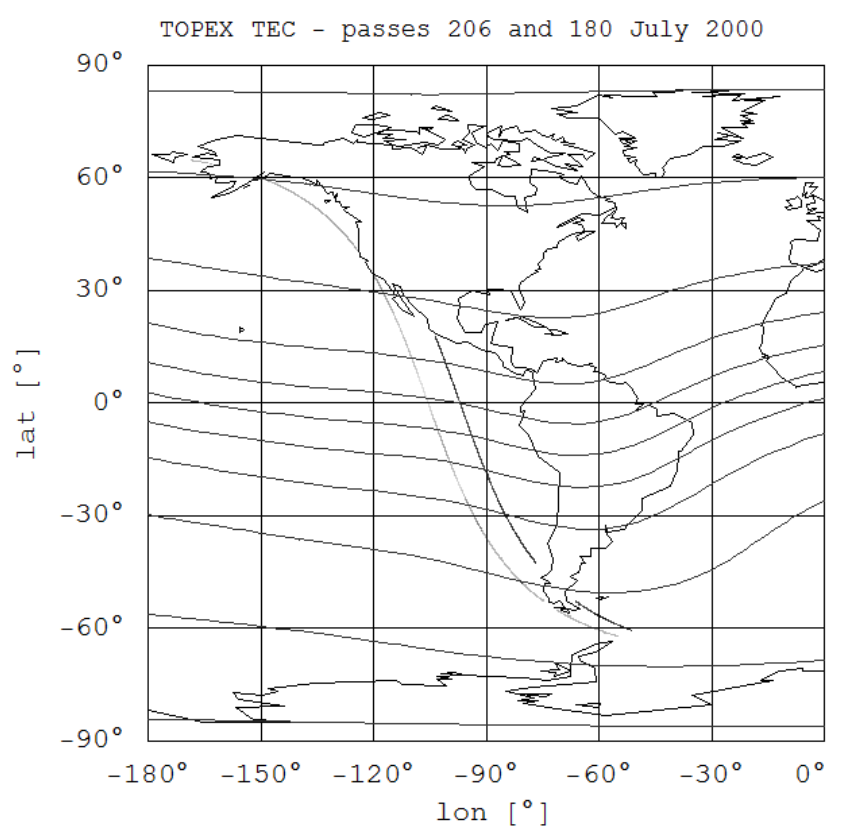

Fig. 1b. Geographical location of the TOPEX passes: 206 (cycle 287) in grey line, crosses the equator at LT 18.33 and pass 180 (cycle 288) in dark line in July 2000 that crosses the equator at LT 16,28 . Isolines represent modip coordinates.

ground and spaced-based instruments, including TOPEX. Their analysis give more emphasis to negative storm effects, due to their longer duration. In the present investigation we consider positive storm effects over the Pacific Ocean at middle-low to equatorial latitudes.

We also evaluate the global signature of ionospheric TEC during the storms by using high resolution interpolated GPS maps or Global Ionospheric Maps (GIM).

In the third section an analysis of vertical TEC spatial gradients variations is included.

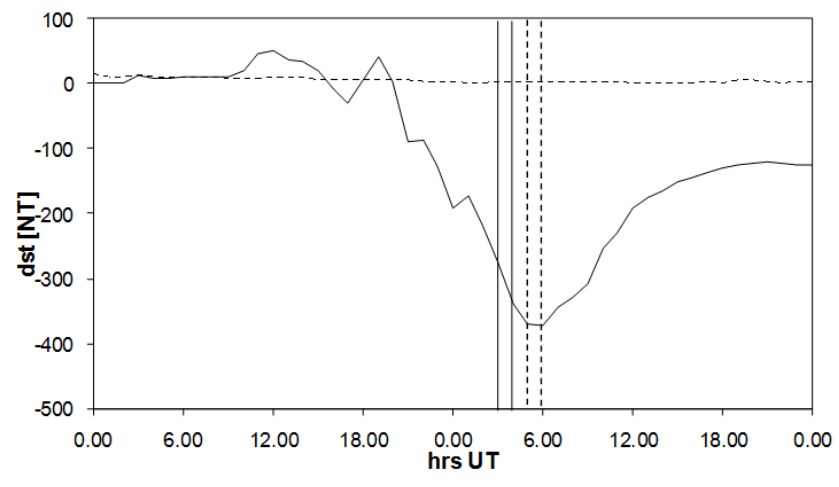

Fig. 2a. $D_{s t}$ indexes of disturbed days 7 and 8 November 2004 in solid line and quiet days 5 and 6 November 2004 in dashed line. The vertical lines indicate beginning and end of TOPEX/Poseidon passes.

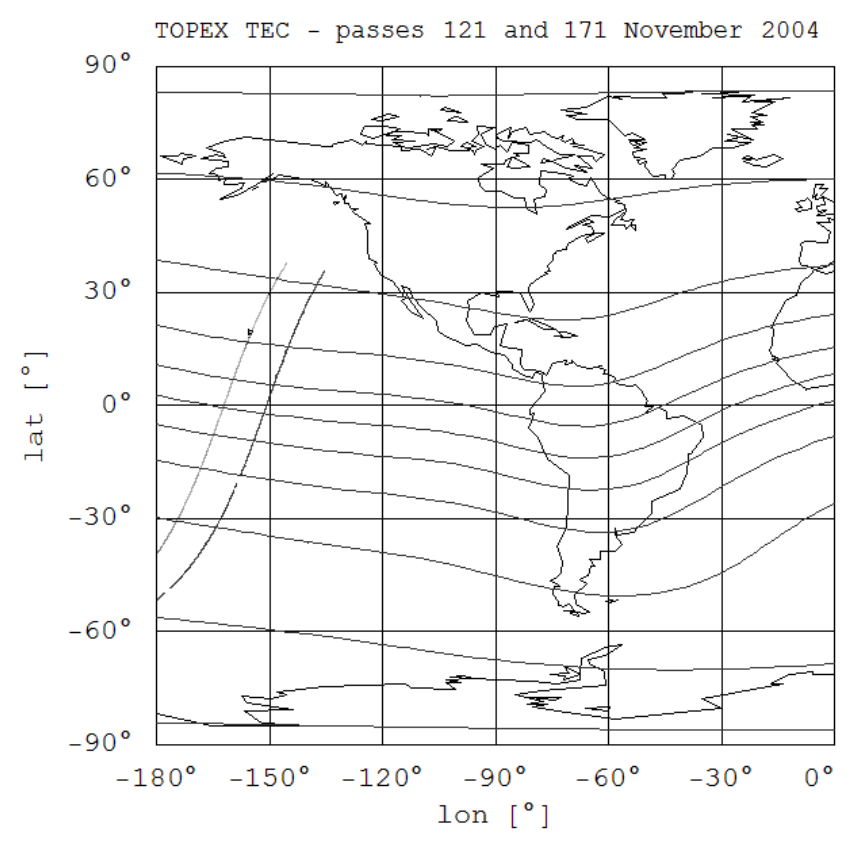

Fig. 2b. Geographical location of the TOPEX passes 121 (grey curve), that crosses the equator at LT 18.58 and 171 (dark curve) that crosses the equator at LT 18.44 both from cycle 447 in november 2004. Isolines represent modip coordinates.

\section{Data sources}

The main objective of TOPEX/Poseidon mission has been tracking global ocean surface topography from a height of about $1330 \mathrm{~km}$, through its dual-frequency altimeter $(\mathrm{Ku}=13.6 \mathrm{GHz}$ and $\mathrm{C}=5.6 \mathrm{GHz})$. In approximately 10 days the satellite complete 127 orbits, or a cycle. The data of each cycle is organized into pass files, numbered from 1 to 254 . A pass is half a revolution of the earth by the satellite from extreme latitude to the opposite extreme latitude. 
Additionally, TOPEX/Poseidon observations provide, as a by-product, vertical TEC values, directly calculated from the ionospheric range delay (Fu et al., 1994). It has to be pointed out that such vertical TEC values are not affected by the conversion factors errors that can be found when vertical TEC is derived from slant GPS TEC data.

TEC measurements have been used in several storm effects studies since vertical TEC constitutes a relatively simple parameter that offers a way to portray the general behaviour of the ionosphere structure, as shown in the review paper by Mendillo (2006) and references therein.

In addition, vertical TEC values obtained from the TOPEX/Poseidon satellite data allow a good meridional cross section of ionospheric behaviour under the effect of the equatorial anomaly.

TOPEX TEC data used in this study correspond to cycles 287 and 288 of year 2000, clearly considered a year of high solar activity (HSA), and cycle 447 of year 2004, with lower solar activity level (LSA). A moving average of $18 \mathrm{~s}$ has been applied, to eliminate short term variations, as indicated by several authors (Imel, 1994; Codrescu, 1999, 2001; Jee et al., 2004; Brunini et al., 2005).

In Figs. 1a and 2a, the $D_{s t}$ magnetic disturbance index is shown to identify the storms phases and pre-storm quiet days. Vertical lines show the duration of the TOPEX/Poseidon passes. The tracks projected over the Earth surface of the selected passes of the satellite can be seen in Figs. 1b and 2b. The contour lines in the maps indicate Modip (modified dip), the coordinate introduced by Rawer 1984, as a geomagnetic coordinate better fitted for ionospheric studies than the magnetic dip itself. This coordinate is defined by Eq. (1).

$\tan (\mu)=I / \sqrt{\cos (\varphi)}$

where, $\mu$ is the modip latitude; $I$ is the magnetic dip; $\varphi$ is the geographic latitude.

The pre-storm quiet passes that have been chosen belong to the quietest days of the month, according to the World Data Center for Geomagnetism of Kyoto, Japan, and considering similar geographical and local time conditions, as can be seen in Figs. $1 b$ and $2 b$.

We have analysed also the vertical TEC GIM maps obtained from GPS data by three different IGS Analysis Centres (IAACs): Jet Propulsion Laboratory (JPL), Centre for Orbit Determination in Europe, Astronomical Institute, University of Berne (CODE) and Polytechnical University of Cataluña (UPC). These use different mathematical approaches to generate grid of vertical TEC with time resolution of $2 \mathrm{~h}$.

CODE approach employs a spherical harmonics expansion to model the global vertical total electron content, using data from about $200 \mathrm{GPS} / \mathrm{GLONASS}$ sites of the IGS and other institutions. CODE provides daily 13 snapshots and GIM in two formats: IONEX (Schaer et al., 1998) and Bernese ION format.

JPL uses an algorithm to routinely calculate vertical TEC having access to more than 100 GPS receivers worldwide.

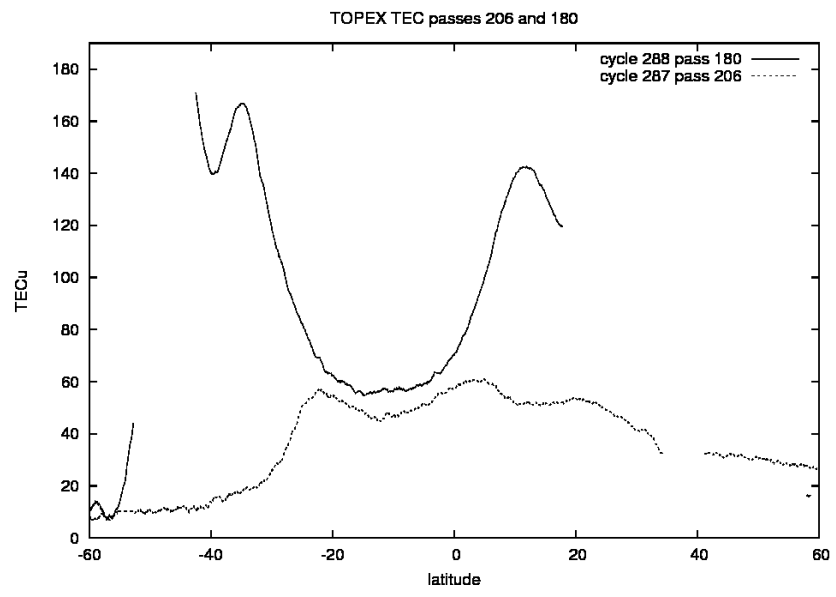

Fig. 3a. Passes 206 (cycle 287 - 6 July 2000) and 180 (cycle 288 15 July 2000) of TOPEX as a function of geographic latitude.

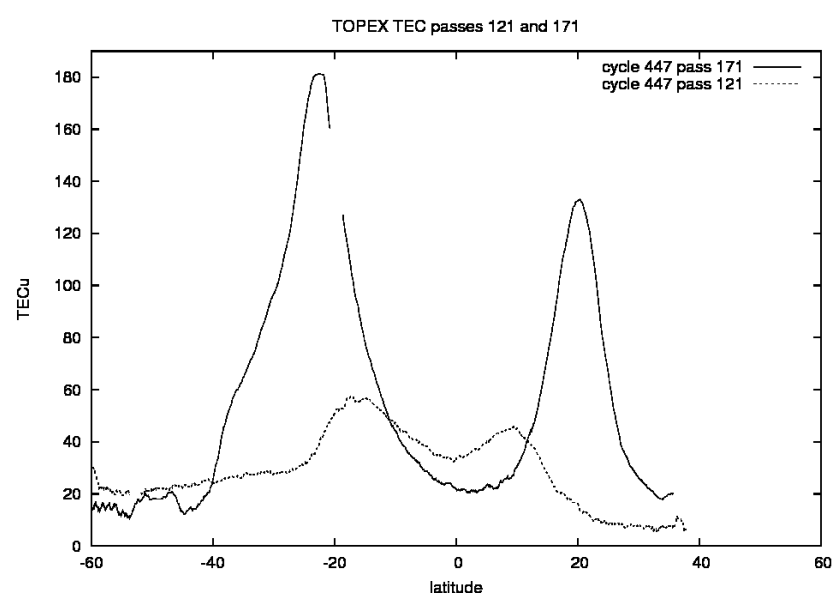

Fig. 3b. Passes 121 (cycle 447 - 6 November 2004) and 171 (cycle $447-8$ November 2004) of TOPEX as a function of geographic latitude.

Thus GIMs from JPL estimate spatial and temporal variability of the global ionosphere, by interpolating the 6-8 simultaneous TEC measurements obtained form each GPS receiver every $30 \mathrm{~s}$ and are created in real-time mode, with an update rate of 5-15 min (http://iono.jpl.nasa.gov).

UPC uses a 2-layer tomographic model with temporal resolution of $2 \mathrm{~h}$ in UT, and spatial resolution of $5^{\circ}$ in LT and $2.5^{\circ}$ in latitude to compute the TEC independently for each of the about 100 worldwide available stations. These regional solutions are combined after with the help of the TEC gradients predicted by IRI, to provide interpolated values in regions where there are no GPS data (see Orús et al., 2003).

More details about these individual IAACs modelling efforts can be found respectively in Schaer (1999), Mannucci et al. (1998) and Hernández-Pajares et al. (1999). 


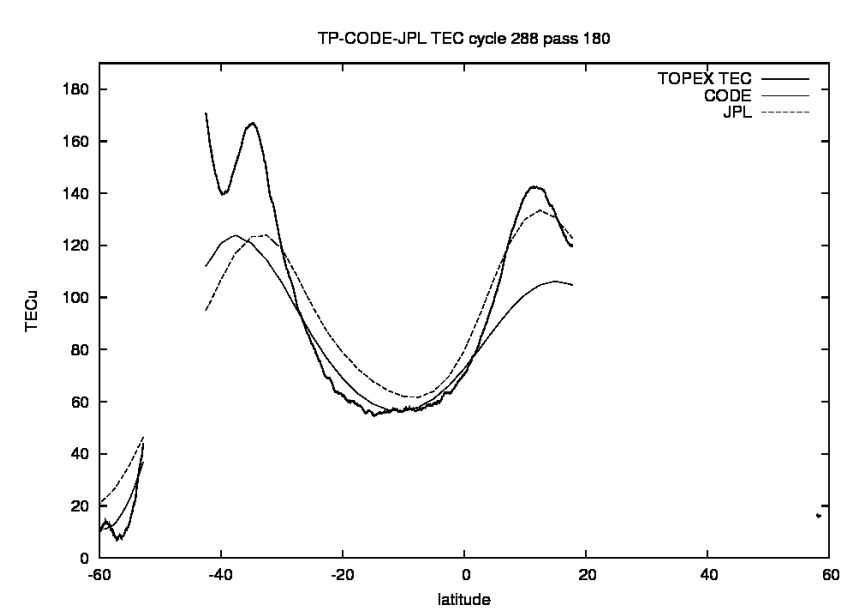

Fig. 4a. Comparison among GIM's TEC models and TOPEX TEC pass during the storm on 15 July 2000 as a function of geographic latitude.

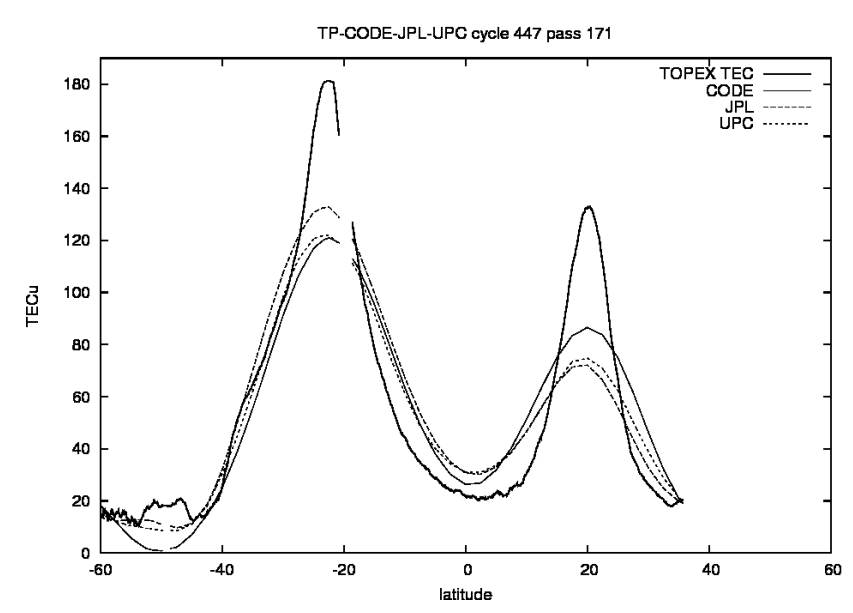

Fig. 4b. Comparison among GIM's TEC models and TOPEX TEC pass during the storm on 8 November 2004 as a function of geographic latitude.

\section{Observations and discussions}

\subsection{Quiet vs. disturbed passes}

As it can be seen in Figs. 1a and 2a, the TOPEX/Poseidon passes selected occur during the main phases of the storms. To examine the difference with quiet conditions, the two passes of July 2000 and November 2004, are compared with quiet conditions passes in Fig. $3 a$ and $b$.

The increase of vertical TEC by a factor of three of the EA crests during the storms is clearly seen. In Fig. 3a dashed curve that represents quiet conditions pass 206 (cycle 287, day 6 July 2000) has a maximum TEC value of 57.27 TECu in the southern crest of the EA $\left(1 \mathrm{TECu}=10^{16}\right.$ electrons $\left./ \mathrm{m}^{2}\right)$ at a geographic latitude: $-22,01^{\circ}$, geographic longitude: $262.8^{\circ}$, modip: $-24.8^{\circ}$; and a maximum of $60.83 \mathrm{TECu}$

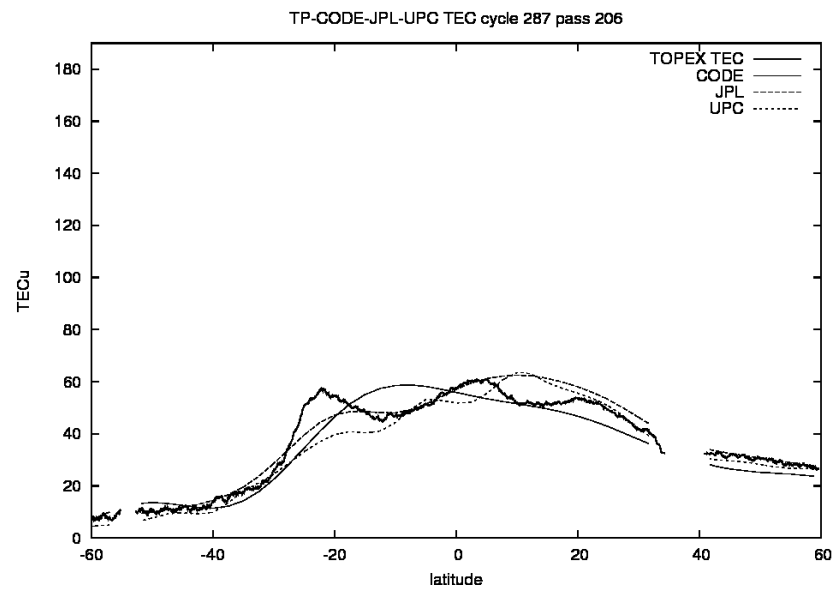

Fig. 4c. Comparison among GIM's TEC models and TOPEX TEC during a pass on 7 July 2000 of quiet pre-storm days as a function of geographic latitude.

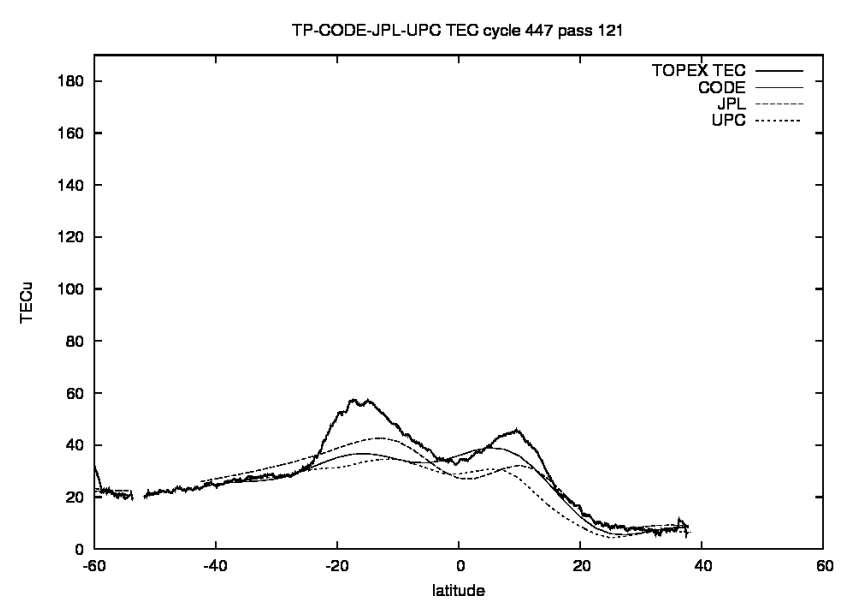

Fig. 4d. Comparison among GIM's TEC models and TOPEX TEC during a pass on 6 November 2004 of quiet pre-storm days as a function of geographic latitude.

at $4.8^{\circ}$ geographic latitude; $252.7^{\circ}$ geographic longitude; modip: $20.48^{\circ}$. While the storm pass 180 in solid line (cycle 288 , day 15 July 2000) exhibits a maximum TEC value of $167 \mathrm{TECu}$ at $-34.6^{\circ}$ geographic latitude; $277.68^{\circ}$ geographic longitude; modip: $-41.38^{\circ}$. In the South Hemisphere; and a maximum of $142.6 \mathrm{TECu}$ at $-34.6^{\circ}$ geog. Lat. $277.68^{\circ}$ geog. Long., modip $-35.46^{\circ}$.

In Fig. $3 \mathrm{~b}$ dashed curve corresponding to quiet conditions pass 121 (cycle $447-6$ November 2004) shows that the maximum TEC for the southern side of the EA is $57.11 \mathrm{TECu}$, located at geographic latitude $-16.85^{\circ}$, geographic longitude $191.46^{\circ}$, modip $-30.89^{\circ}$; while the northern crest has 45.83 TECu of maximum at geographic latitude $9.49^{\circ}$; geographic longitude $201.14^{\circ}$; modip $19.80^{\circ}$. Solid line represents storm pass 171 (cycle 447 - 8 November 2004) with a maximum TEC at low latitudes of $180.88 \mathrm{TECu}$ in $-21.76^{\circ}$ 
geographic latitude, $200.76^{\circ}$ geographic longitude; modip $-35.14^{\circ}$.

Both figures indicate positive storm effects near the time of maximum decrease of $D_{s t}$ values. The effects experienced are larger in the Southern Hemisphere. Also evident is the tendency of the EA crests to move towards the poles by several degrees and with substantially larger values with respect to the quiet days passes.

These observations are in line with simulations performed by Lin et al. (2005), who integrated Sheffield University Plasmasphere-Ionosphere Model (SUPIM) electron densities when $\boldsymbol{E} \times \boldsymbol{B}$ drift plus equatorward winds are considered, showing the poleward expansion of the EA peaks and the ratio of TEC increase between storms and pre-storms conditions.

\subsection{GIM's vs. TOPEX}

As it is known the different GIM techniques allow combining GPS-based measurements to generate global modelled ionospheric maps of vertical TEC.

Global TEC maps were obtained by the different modelling approaches from ground stations GPS data with the purpose of showing their performance and particularly their interpolation accuracy in comparison with the observed TOPEX/Poseidon data. The ionospheric conditions analysed in the present paper can be considered as worst case for the GIMs, due to the TOPEX observations are typically far from the GPS ground receivers and can be considered as snapshots.

In Fig. 4 it is seen that in general, all of the GIMs maps are prone to underestimate the TEC in the EA crests region both in disturbed and quiet conditions. Nevertheless, a better agreement is found between GIMs derived TEC and TOPEX during quiet conditions passes (Fig. $4 \mathrm{c}$ and d), with an underestimation of a few TECu at the EA crests. In the case of CODE map the EA peaks are absent. While in the reproduction of storms passes discrepancies are clearer in the area of the EA, with a difference close to $40 \%$ in both crests for the CODE solution and less for the northern peak for the JPL map (see Fig. 4a and b). Note that there is no UPC solution for 15 July 2000.

\subsection{TEC rate of change and spatial gradients}

Space Based Augmentation Systems (SBAS) operations can be seriously affected in their range accuracy in regions where high values of TEC and large time and spatial gradients of TEC are present (Walter et al., 2004; Kintner and Ledvina, 2005). SBAS broadcast equivalent Grid Ionospheric Vertical Delays (GIVD) to correct ionospheric delays. Ionospheric Grid Points (IGP) are given every $5^{\circ} \times 5^{\circ}$. Ionospheric Pierce Points (IPP) are defined as the intersection of the straight line between the satellite and the receiver with a thin shell ionosphere placed at $350 \mathrm{~km}$ of altitude. Ionospheric range

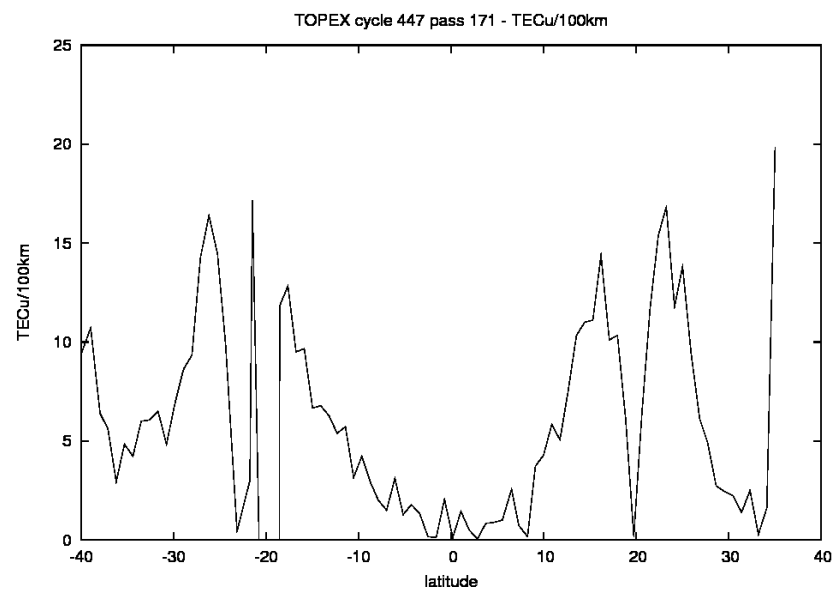

Fig. 5a. TEC spatial gradients correspond to TOPEX pass on storm day (8 November 2004, pass 171 , cycle 447$)$.

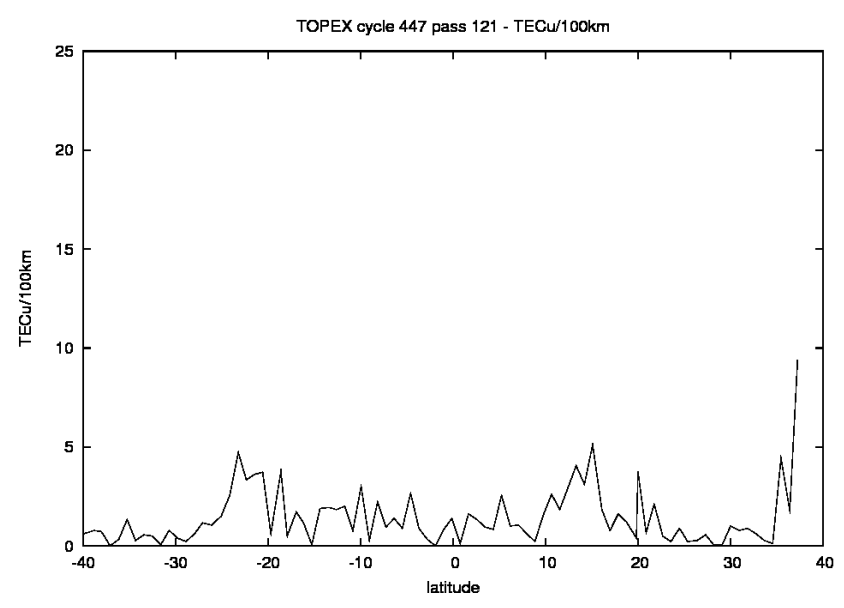

Fig. 5b. TEC spatial gradients correspond to TOPEX pass on a quiet prestorm day (6 November 2004, pass 121, cycle 447).

delay is directly proportional to TEC and $6.15 \times 10^{16} \mathrm{el} / \mathrm{m}^{2}$ of TEC (6.15 TEC units) are equivalent to $1 \mathrm{~m}$ of range delay at L1 frequency. From GIVDs users interpolate to obtain the equivalent vertical delay at each IPP using a conversion formula that works appropriately during nominal quiet conditions where spatial gradients of TEC are small. Where gradients are much larger it may be expected that the range delay correction method used by SBAS would not provide adequate ionospheric corrections (Klobuchar et al., 2002).

These conditions are found particularly at low latitudes and during geomagnetic storms. Range delay correction method used by SBAS, would not provide adequate ionospheric corrections under such conditions.

The TEC rate of change (the observable) obtained from TOPEX derived TEC can be converted in TEC change with distance projected over the Earth surface. This represents a reasonable approximation of the measure of spatial gradients of TEC. 
On the contrary, it has to be noted that the use of GPS derived TEC rate of change does not offer a way to separate effectively time gradients from spatial gradients of TEC.

Figure $5 \mathrm{a}$ and $\mathrm{b}$ shows that the spatial gradients of TEC at low latitudes vary strongly between quiet (pass 121 of 6 November 2004) and storm (pass 171 of 8 November 2004) conditions. This result appears to be in contrast with the observations of Walter et al. (2004) for conditions observed over Brazil. These authors do not see major differences between gradients calculated for the region of the EA crests under quiet and storm conditions. The large gradients calculated for the storm conditions (Fi. 5a) are in line with the sharp EA crests seen in the TOPEX vertical TEC values along the storm condition pass. In turn low gradients during quiet conditions correspond to a much less developed EA. It must be noted that normal RMS values of TEC spatial gradients over the area covered by the American SBAS (WAAS) are equivalent to about $3 \mathrm{TECu} / 100 \mathrm{~km}$ (Komjathy et al., 2003).

\section{Conclusions}

As previous studies have shown, middle and low latitudes ionosphere can be affected with an EA expanded poleward and became more pronounced during an important storm event, (Tanaka, 1986; Abdu, 1997).

We have chosen two major geomagnetic storms that took place under different seasons and solar activity levels, on 15 July 2000 and 8 November 2004, and identified the TOPEX/Poseidon satellite passes to contrast its TEC measurements with another passes in quiet pre-storm conditions. The behaviour in both cases is remarkably consistent, showing an increased EA by roughly a factor of three, with its crests moved poleward with a separation of several degrees.

We considered TOPEX TEC observations as "experimental" data to be compared with GIM's modelled results. As Orús et al. (2002) have pointed out, TEC values obtained from the maps are significantly smaller than TOPEX measurements. However, JPL maps derived TEC shows in general a better agreement with those measurements. These differences could be due to the interpolation scheme used by the models that construct the different GIM's. TOPEX TEC data shows the existence of steep crests with higher values of vertical TEC than those given by the GIMs.

Our study also shows large values of the spatial gradients of TEC at low latitudes during geomagnetic storms in correspondence with the well developed crest of TEC. This indicates potential difficulties in the operation of satellite augmentation systems used for satellite navigation like the US WAAS and the European EGNOS under geomagnetic storm induced ionospheric conditions.
Acknowledgements. Authors want to thank the IAACs for the GPS data and JPL's Physical Oceanography Distributed Active Archive Centre (PO.DAAC) for TOPEX data. In special they thank to Francisco Azpilicueta for the generation of the GIMs and Patricia Doherty for the TEC TOPEX data. Y. Migoya Orué thansk J. Grassberger and topical Editor K. Kauristie for their assistance in evaluating this paper.

Topical Editor K. Kauristie thanks C. Brunini and two other anonymous referees for their help in evaluating this paper.

\section{References}

Abdu, M. A.: Major phenomena of the equatorial ionosphere thermosphere system under disturbed conditions, J. Atmos. Solar Terr. Phys., 59(13), 1505-1519, 1997.

Basu, S., Groves, K. M., Yeh, H.-C., Su, S.-Y., Rich, F. J., Sultan, P. J., and Keskinen, M. J.: Response of the equatorial ionosphere in the South Atlantic region to the great magnetic storm of July 15, 2000, Geophys. Res.Lett., 28, 3577-3580, 2001.

Brunini, C., Meza, A., and Bosch, W.: Temporal and spatial variability of the bias between TOPEX- and GPS-derived TEC, J. Geod., v79(4-5), 175-188, doi:10.1007/s00190-005-0448-z, 2005.

Buonsanto, M. J.: Ionospheric storms- a review, Space Sci. Rev., 88, 563-601, 1999.

Codrescu, M. V., Palo, S. E., Zhang, X., Fuller-Rowell, T. J., and Poppe, C.: TEC climatology derived from TOPEX/Poseidon measurement, J. Atmos. Solar Terr. Phys., 61, 281-298, 1999.

Fu, L.-L., Christensen, E. J., Yamarone Jr., C. A., Lefebvre, M., Ménard, Y., Dorrer, M., and Escudier, P.: TOPEX/POSEIDON mission overview, J. Geophys. Res., 99(C12), 24369-24381, 1994.

Hernández-Pajares, M., Juan, J. M., and Sanz, J.: New approaches in global ionospheric determination using ground GPS data, J. Atmos. Solar Terr. Phys., 61, 1237-1247, 1999.

Hunsucker, R. D. and Hargreaves, J. K.: The high-latitude ionosphere and its effects on radio propagation, Cambridge University Press, 2003.

Imel, D. A.: Evaluation of the TOPEX/POSEIDON dual-frequency ionospheric correction, J Geophys. Res., 99(C12), 24895-24906, 1994.

Jee, G., Schunk, R. W., and Scherliess, L.: Analysis of TEC data from the TOPEX/Poseidon mission, J. Geophys. Res., 109, A01301, doi:10.1029/2003JA010058, 2004.

Kil, H., Paxton, L. J., Pi, X., Hairston, M. R., and Zhang, Y.: Case study of the 15 July 2000 magnetic storm effects on the ionosphere-driver of the positive ionospheric storm in the winter hemisphere, J. Geophys. Res., 108(A11), 1391, doi:10.1029/2002JA009782, 2003.

Kintner, P. M. and Ledvina, B. M.: The ionosphere, radio navigation, and global navigation satellite systems, Adv. Space Res., 35(5), 788-811, 2005.

Klobuchar, J. A., Doherty, P. H., Bakry El-Arini, M., Lejeune, R., and Dehel, T.: Total Electron Content effects on GNSS augmentation systems, URSI 2002, General Assembly Proceedings, 2002.

Komjathy, A., Sparks, L., Mannucci, A. J., and Pi, X.: On the Ionospheric Impact of Recent Storm Events on Satellite-Based Augmentation Systems in Middle and Low-Latitude Sectors, ION 
2003 GPS/GNSS Meeting Proceedings, 2769, Oregon Convention Center, Portland, Oregon, 9-12 September 2003.

Lin, C. S. and Yeh, H.-C.: Satellite observations of electric fields in the South Atlantic anomaly region during the July 2000 magnetic storm, J. Geophys. Res., 110, A03305, doi:10.1029/2003JA010215, 2005.

Lin, C. H., Richmond, A. D., Liu, J. Y., Yeh, H. C., Paxton, L. J., Lu, G., Tsai, H. F., and Su, S.-Y.: Large-scale variations of the low-latitude ionosphere during the October-November 2003 superstorm: Observational results, J. Geophys. Res., 110, A09S28, doi:10.1029/2004JA010900, 2005.

Lynn, K. J. W., Sjarifudin, M., Harris, T. J., and Le Huy, M.: Combined TOPEX/Poseidon TEC and ionosonde observations of negative low-latitude ionospheric storms, Ann. Geophys., 22, 2837-2847, 2004,

http://www.ann-geophys.net/22/2837/2004/.

Mannucci, A. J., Wilson, B. D., Yuan, D. N., Ho, C. H., Lindqwister, U. J., and Runge, T. F.: A global mapping technique for GPSderived ionospheric total electron content measurements, Radio Sci., 33, 565-582, 1998.

Mendillo, M.: Storms in the ionosphere: Patterns and processes for total electron content, Rev. Geophys., 44, RG4001, doi:10.1029/2005RG000193, 2006.

Orús R., Hernández-Pajares, M., Juan, J. M., Sanz, J., and GarcíaFernández, M.: Performance of different TEC models to provide GPS ionospheric corrections, J. Atmos. Solar-Terr. Phys., 64, 2055-2062, 2002.
Orús, R., Hernández-Pajares, M., Juan, J. M., Sanz, J., and GarciaFernandez, M.: Validation of the GPS TEC maps with TOPEX data, Adv. Space Res., 31(3), 621-627, 2003.

Prölss, G. W.: Ionospheric F-region storms, in: Handbook of atmospheric Electrodynamics, vol. 2, edited by: Volland, H., 195248, CRC press, Boca Raton, FL, 1995.

Rawer, K. (Ed.): Encyclopedia of Physics, Geophysics III, Part VII, Springer-Verlag, pp. 389-391, 1984.

Schaer, S., Gurtner, W., and Feltens, J.: IONEX: The IONosphere Map Exchange Format Version 1, Proceedings of the 1998 IGS Analysis Centers Workshop, ESOC, Darmstadt, Germany, 9-11 February 1998.

Schaer, S.: Mapping and Predicting the Earth's Ionosphere Using the Global Positioning System, Dissertation, Astronomical Institute, University of Berne, Berne, Switzerland, 1999.

Walter, T., Datta-Barua, S., Blanch, J., and Enge, P.: The Effects of Large Ionospheric Gradients on Single Frequency Airborne Smoothing Filters for WAAS and LAAS, ION 2004 National Technical Meeting Proceedings, Stanford University, 103, 2004.

Tanaka, T.: Low-latitude ionospheric disturbances: Results for March 22, 1979, and their general characteristics, Geophys. Res. Lett., 13(13), 1399-1402, 1986.

Yizengaw, E., Moldwin, M. B., Dyson, P. L., and Immel, T. J.: Southern Hemisphere ionosphere and plasmasphere response to the interplanetary shock event of 29-31 October 2003, J. Geophys. Res., 110, A09S30, doi:10.1029/2004JA010920, 2005. 